\title{
A SEMI-AUTOMATIC METHOD FOR CASE ACQUISITION IN CBR A STUDY IN OIL WELL DRILLING
}

\begin{abstract}
Oil well drilling operation is a complex process, in which there are always new lessons learned during drilling operation. Casebased reasoning (CBR) is an approach to problem solving that recalls previous experiences. Whenever the process is running smoothly, or is failing, the experiences gained during such episodes are valuable and should be stored for later re-use. This paper presents a methodology for automatic case building and case discrimination to obtain a robust case-based reasoning and learning system. To achieve this, a platform that integrates cases with general domain knowledge was used and employed in the oil well drilling domain. The implemented system showed the efficiency of the methodology for capturing and reusing previous experiences.
\end{abstract}

\section{KEY WORDS}

Case-based reasoning, oil well drilling, knowledge discovery

\section{INTRODUCTION}

In case-based reasoning (CBR) new problems are solved by retrieving related situations from cases solved in the past. Cases are the core of the reasoning process, in which problematic situations are explained. In CBR terminology, a case denotes a specific problem situation (previously experienced situation), which has been captured and stored in a way that enables reusing for solving of future problems. Some CBR methods assume a rather large amount of widely distributed cases in its case base, while others are based on a more limited set of typical cases [1]. In most CBR approaches, an abnormal situation is considered to make a case. It means that whenever a new problem occurs, a case is built and stored in the case database, to be used for the reasoning routine.

There are a lot of wells drilled every day to supply world oil consumption. Oil well drilling is a complex and expensive operation. Over the last few years CBR has been applied in oil well drilling to reduce the cost and increase the safety of the drilling operation [2, 3]. Skalle et al. [4] introduced how to make a case in oil well drilling, mostly based on static parameters. Static parameters do not change much between measurements. Abdollahi et al. [5] used Skalle and his colleagues' template to make cases in which well integrity problems were in focus. Later Shokouhi et al. [6] focused on hole cleaning problems and introduced case features which consisted of dynamic parameters that can change more often, in addition to static parameters. This case structure was able to describe the problematic situations quite well. However, only few cases existed in their database, and testing should be performed with more cases. This was the first motivation of the research work presented here. Therefore, different cases in terms of severity of the problems are constructed in an automatic way. A methodology that strengthens both reasoning and learning simultaneously is introduced in this paper. A semi-automatic learning method is also incorporated to enable sustained learning by updating the case database.

Problems frequently occur when drilling several kilometers through different geological formations. Real-time data is used to keep the drilling process run smoothly, with low risk of downtime (i.e. stopped drilling). In addition to real-time data, documents such as daily drilling reports (DDR) are reported for every single well. They are valuable resources in which the solutions for most of the past problems are expressed. Our main idea is to bind the measurements and knowledge in such as daily drilling reports to solve problems by means of CBR, as illustrated in Figure 1. Mutual dependencies of data and knowledge are essential in data interpretation and learning of knowledge.

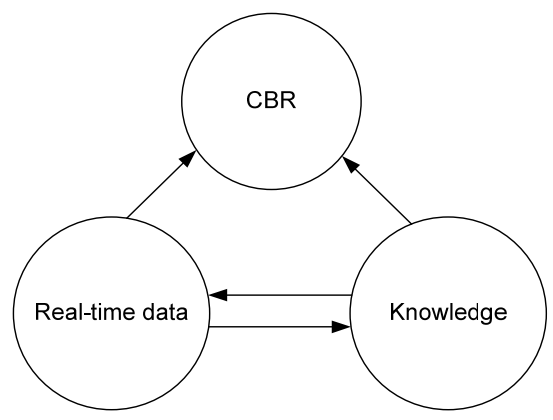

Figure 1. Binding real-time data and knowledge of drilling personnel by means of CBR system.

The second motivation is to extract information from daily drilling reports. Guilherme et al. [7] presented a methodology to organize and extract information from DDRs. It is required to know where and when the extraction is needed. Through a classification method, anomalies in cases are determined.

This paper applies the methodology with focus on hole cleaning problems, due to the high number of parameters influencing hole cleaning and the complex mechanisms involved. To do so, the CREEK platform was used. The CREEK system is an architecture for case-based problem 
solving, targeted at addressing problems in open and weak theory domains [8]. The work presented here has two sides. The first is associated with the methodology of the case building process integrated with a classification routine to reuse the cases and learn from the cases. It presents a structure to utilize different experiences and lessons learned from previous stored cases. The second side demonstrates applicability of the method in the oil well drilling domain, targeted at reducing unwanted downtime during hole cleaning.

This paper is organized as follows. In chapter 2 we introduce the oil well drilling process, and explain the complexity and feasibility of employing the CBR approach. In chapter 3 we present the case generation, problem-solving, and learning approach. That section specifies case generation in detail by defining the case classification and case retrieval processes. Chapter 4 illustrates the applicability of the methodology in re-using the compiled experiences. The last chapter summarizes and concludes the paper.

\section{OIL WELL DRILLING}

\subsection{General overview}

Drilling a well section, i.e. a part of the drilled hole, typically in the range of 500-2000 meters long, takes several days. Generally speaking, a drilling operation includes different activities as follows;

\section{1- Drilling: The process of making a new hole.}

2- Connection: The process of adding a new drill pipe unit $(10-30 \mathrm{~m})$ to the drillstring.

3- Tripping In/Out: The act of running the drillstring into/ out of the hole.

4- Circulating: Pumps are turned on to enable the drilling fluid to circulate up and down.

5- Reaming: Return to total depth with pumps on, pipe rotating and/or weight on the drill bit.

6- Backreaming: Return back from total depth with pumps on, pipe rotating and/or weight on the drill bit.

Real-time data include observed data collected from sensors. They cannot explain deviatory episodes alone. But they need to be interpreted in such a way that they can be understandable and informative. Some of these data are implemented to distinguish what kind of activity goes on when a case occurs. The rest are also utilized to define some of the case's features. Drilling activities are interpreted based on the different parameters like rotation of the drilling bit, pumping the drilling fluid from the drill pipe and back through the annular, position of the drilling bit and traveling block. Table 1 shows typical drilling parameters and variation of parameters for automatic interpretation of the drilling activities. For example, when the rotation and pump are on, hook load is equal to weight of drill string minus weight on bit (WOB), and block moves down, the activity will be inferred as drilling.
TABLE 1. DEFINITION OF THE MOST FREQUENT OCCURRING DRILLING ACTIVITIES WHERE: $\mathrm{B}=$ WEIGHT OF THE TRAVELLING BLOCK, WDS=WEIGHT OF DRILL STRING. DEFINITION OF SYMBOLS ARE: $\checkmark=$ ACTIVE PARAMETER, $\boldsymbol{x}=$ INACTIVE, $\uparrow=$ MOVING UP AND $\downarrow=$ MOVING DOWN.

\begin{tabular}{|l|c|c|c|c|}
\hline Activity & Rotating & Pumping & $\begin{array}{c}\text { Block } \\
\text { movement }\end{array}$ & Hook load \\
\hline Drilling & $\checkmark$ & $\checkmark$ & $\downarrow$ & WDS-WOB \\
\hline $\begin{array}{l}\text { Tripping in } \\
\text { (RIH) }\end{array}$ & $\mathbf{x}$ & $\mathbf{x}$ & $\downarrow$ & WDS - friction \\
\hline $\begin{array}{l}\text { Tripping Out } \\
\text { POOH) }\end{array}$ & $\mathbf{x}$ & $\mathbf{x}$ & $\uparrow$ & WDS + friction \\
\hline $\begin{array}{l}\text { Reaming } \\
\text { Backreaming }\end{array}$ & $\checkmark$ & $\checkmark$ & $\uparrow$ & $\begin{array}{c}\text { WDS - } \\
\text { (WOB+friction) }\end{array}$ \\
\hline Connection & $\mathbf{x}$ & Either & $\mathbf{x}$ & $\begin{array}{c}\text { WDS+ } \\
\text { (WOB+friction) }\end{array}$ \\
\hline Circulating & $\mathbf{x}$ & $\checkmark$ & $\mathbf{x}$ & WDS \\
\hline
\end{tabular}

Some distinct problems normally happen while a certain activity takes place. This is the main reason for determining the activity when a case is made during the drilling operation. For example, took weight will take place where there is a reduced hole diameter and the activity involved is clearly tripping in (RIH). The activity recognition will not only help to distinguish among problems but also will help to apply the right repair procedures.

\subsection{Description of problem}

When the drilling of a well begins, the drilling fluid is required to transport all the produced materials from the bottom of the well to the surface via the annular gap between the drill pipe and the wellbore wall. If hole cleaning is insufficient, i.e. intentionally and unintentionally produced materials cannot be transported to the surface, it culminates in difficulties such as pack-off. This is a serious situation caused by building up of materials inside the hole, with reduced hole diameter as a result. The situation can turn into unscheduled and expensive events like stuck-pipe i.e. the drill pipe cannot rotate or move up or down. Stuck-pipes necessitate time consuming repair actions.

The drilling process increases in complexity with increasing hydrocarbon reservoir depths and field complexity. At the same time information flow increases in volume and intensity. Failures are bound to occur leading to loss of time while repairing the failures to return the process back to its normal state. Statistical analysis of the number of stuck-pipe from 1991 to 2007 has shown that this problem decreased, credited to technological progress and past experiences (see Figure 2). However, the number of the stuck-pipes fluctuates over time, although the overall trend reflects a decline in stuck-pipes episodes. Re-using of past experience enables us to keep the number of problems low and avoid repetition of similar problems. It leads to avoiding fluctuation of the problems by time as can be seen from Figure 2 . 


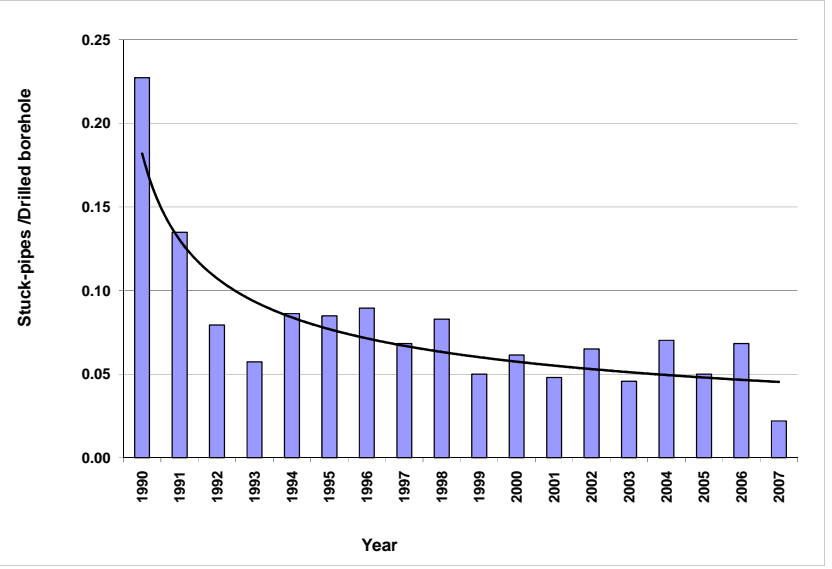

Figure 2. Number of stuck-pipes per drilled wellbores from 1991 to 2007.

\section{CASE-BASED REASONING}

As mentioned, case-based reasoning is an approach to solving new problems by adapting and using solutions that were used to solve previous problems. The CBR cycle consists of four steps; retrieve, reuse, revise and retain[1]. The retrieval task starts with a (partial) problem description, and ends when a best matching previous case has been found. CBR has been widely applied in different domains such as law [9], medicine [10], music [11] and petroleum engineering [12, 13]. Our focus is to employ case-based reasoning in oil well drilling to reduce the unwanted downtime and consequently the cost of drilling operation.

\subsection{Similarity assessment for CBR}

Two different mechanisms are used to compute the values of similarity between a new case and a case in the case base. Linear similarity is used for those features that have numeric values. Semantic similarity is being used for direct or indirect match of symbolic feature values. It is relying on concept abstraction. Linear and direct symbolic similarity measurements are used for case matching within the CBR platform (for more information see [6]).

Basic similarity among cases, a solved case and an unsolved case, is computed by the following equation.

$$
\operatorname{sim}\left(C_{I N}, C_{R E}\right)=\frac{\sum_{i=1}^{n} \sum_{j=1}^{m} \operatorname{sim}\left(f_{i}, f_{j}\right) \times \text { relevancefactor }_{f_{j}}}{\sum_{j=1}^{m} \text { relevancefactor }_{f_{j}}}
$$

$\mathrm{C}_{\mathrm{IN}}$ and $\mathrm{C}_{\mathrm{RE}}$ are the input and retrieved cases, $\mathrm{n}$ is the number of findings in $\mathrm{C}_{\mathrm{IN}}$, $\mathrm{m}$ is the number of findings in $\mathrm{C}_{\mathrm{RE}}$, $f_{i}$ is the $i^{\text {th }}$ finding in $C_{I N}, f_{j}$ the $j^{\text {th }}$ finding in $C_{R E}$.

The relevance factor is a number that represents the weight of a feature for a stored case. The relevance factor of each feature was defined according to the feature's importance for the case description.

\subsection{Re-using of the past experiences}

Reasoning by using past cases is a powerful and frequently applied way to solve problems for human, especially when there are many parameters involved making the decision ambiguous. Machine learning concerns the development of algorithms for keeping lessons gained from previous cases. CBR is also a form of machine learning where storing and integrating a new case in the case base adds to the system's knowledge. The following semi-automatic learning method has been implemented to retrieve the case, assign a new class for an unsolved case, and if necessary store a new case.

Figure 3 illustrates how the methodology works. It starts with discretization of a new case in defined intervals (intervals of $40 \mathrm{~m}$ in this study) and collects values of the case's features for the new case. The new case is compared with previously stored cases. If there is a similar case in the case database, then the new case is placed in the same class as the similar retrieved case. Otherwise, an investigation is done by experts to define a new class. In the last part of the CBR cycle, the new solved case will be retained to be used for future problem solving. In this way, reasoning and learning are glued together. This is the main advantage of the methodology. In addition, the indexing structures in the case database are dynamically updated, so that new experiences strengthen the CBR system.

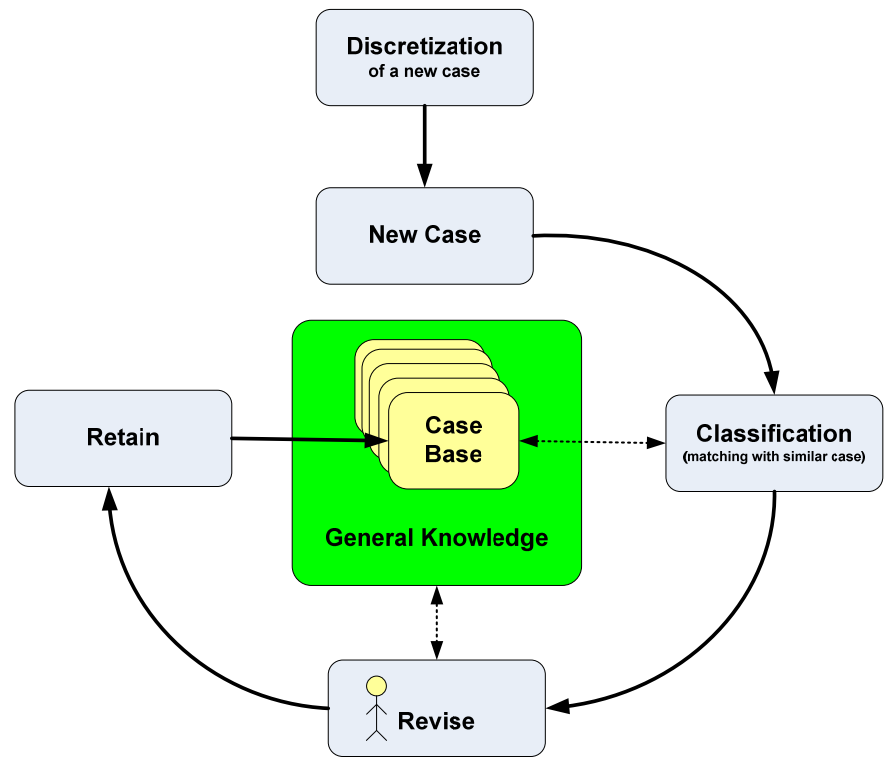

Figure 3. Re-use of the past experiences by combining of a CBR and a classifying approach.

\subsection{Classifying cases}

The knowledge of experts is presented in the form of cases that summarize the drilling experiences of the experts. Whenever a new case is made, the new case will be compared with previously solved cases using the case's features, as outlined in Figure 4. A classification algorithm (illustrated in Figure 4) is implemented which organizes the cases to facilitate constructing the case database. Another benefit from forming classes is to provide a basis for the subsequent sequence building, i.e. equally classified cases happened at the 
same drilling intervals, but that goes beyond the aim of this paper.

We will classify the cases into particular classes by our existing case-based reasoning system. The retrieval process is responsible for identifying class. A case is then compared to other cases in the case database, where each case is composed of several features and an associated action. In the flowchart, the threshold, $\mathrm{T}$, may be set in a range from 0 to $100 \%$. When
$\mathrm{T}$ equals 0 , all cases will be classified in one class. For $\mathrm{T}$ equals $100 \%$, the number of classes can become identical with or less than the number of cases. With respect to the threshold (here the threshold was set to $70 \%$ ), whenever there is no matched case for a new case, a new class is formed by the expert(s) and this new case will be the first member of the formed class.

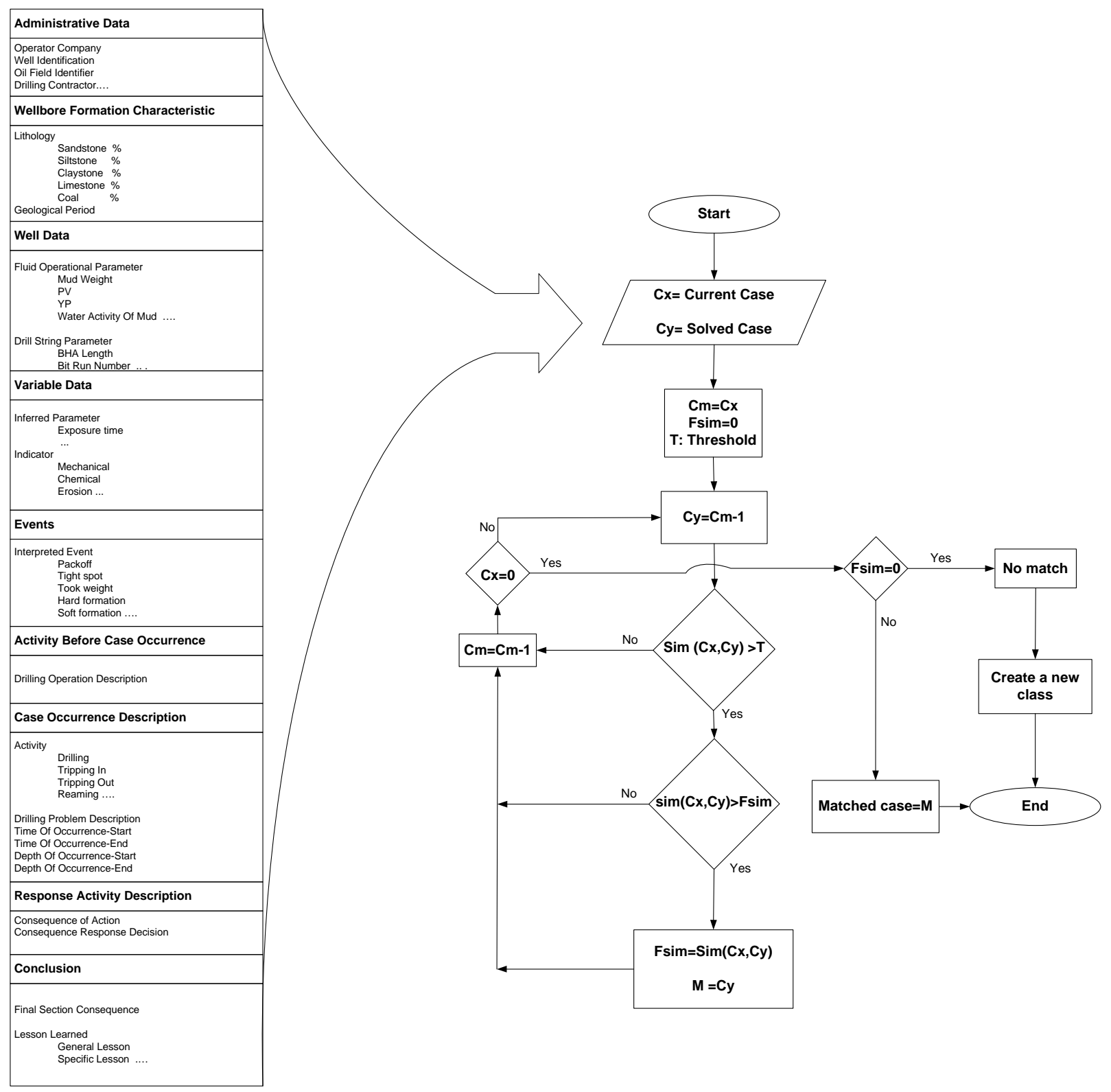

Figure 4. An analogical algorithm to classify the cases (right) accompanied by case structure (left).

As an example, assume that there are four cases named $\mathrm{C} 1$ to $\mathrm{C} 4$ in our case database. A new case (C5) appears to be compared. According to the approach C5 and C4 will be compared first. If the similarity between them is higher than the threshold value then C5 will be kept as a matched case. This process will be repeated for the others; C3, C2 and C1. When the process is completed the unsolved case is classified in the same class as the best matched case. If there is no similar case to the unsolved case, a new class will be created and C5 (the new case) becomes the first member of this class. 


\subsection{Revise}

After building a new case and forming a class through the classification, a next step is to consolidate the results across documents. Daily drilling reports are prepared by the operator's drilling engineers to describe the drilling and completion status. The system interprets the results from daily drilling reports, by successively evaluating by experts, shown in Figure 5. The process of extracting may be done either automatically or manually[7]. The bold arrows represent the way that has been used in this study. We will carefully study the automatic extraction of information from DDRs by means of ontologies, search-based approaches, and text mining.

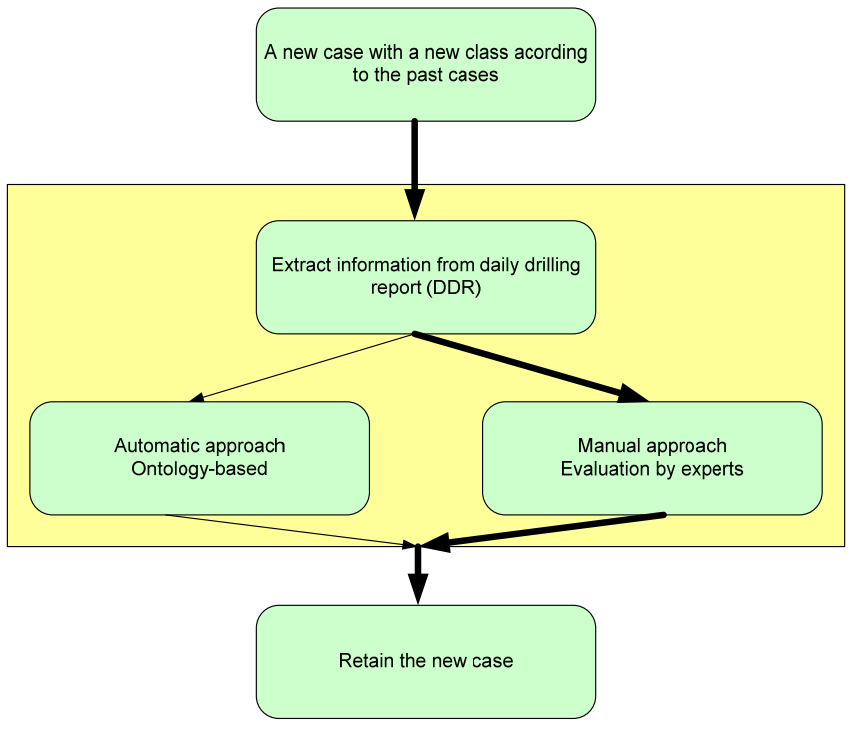

Figure 5. The workflow for evaluation of the case classification.

\section{APPLICATION OF THE METHODOLOGY IN THE OIL WELL DRILLING}

A lot of wells are being drilled every day. It is crucial to drill a hole faster and safer. To avoid the repetition of mistakes or any problems that happened in the past, CBR is a perfect technology in this business. For some problems best-practices are available, but for less common problems, solutions are not available. To evaluate the model, the methodology is applied to the problem of hole cleaning in oil well drilling.

Due to the number of parameters influencing hole cleaning operation and the complex mechanisms involved, the phenomenon has not yet been fully understood [14]. For that reason, hole cleaning problems were chosen to be investigated by means of CBR. Following this choice we have investigated a well located in the North Sea for the methodology.

\subsection{Case structure}

The Case structure presented by Shokouhi et al. [6, 15] was utilized with some modifications. The case structure is shown in Figure 4 (left part). The case structure consists of important groups of features for defining a case. Selecting the adequate factors can provide considerably better case definition for a case retrieval process. Each case comprises: (i) Administrative data, (ii) wellbore formation characteristic, (iii) well data, (iv) variable data, (v) events, (vi) activity before case occurrence, (vii) case occurrence description, (viii) response activity description, and (ix) conclusion.

\subsection{Model evaluation}

Drilling of an offshore well takes typically a month. But unwanted events will lead to downtime. Figure 6 depicts the drilling operation for $1120 \mathrm{~m}$ open hole length section in bit measured depth (MD) and time scale. Holes are rarely drilled vertically these days, and measured depth is the total depth along the path of the wellbore i.e. the length of the drill string. Every 40 meters have been chosen for data analysis and case building length.

The upmost problem in deviated wellbores (inclination more than 30o) is hole cleaning. The transport efficiency or solids removal rate is low in deviated wellbore sections. The scenario in deviated wells is that solid materials are settling along the wellbore wall during drilling activity. When the drill string is moved axially, large diameter elements of the drill string, called bottom hole assembly (BHA), such as the drill bit and stabilizers, tend to scrape the solid materials bed, thereby causing the formation of plugs of cuttings which give rise to pack-offs, and to a continuous need for operations such as backreaming, wiper trips and reduced rate of penetration (ROP) [16].

Our methodology was employed on a deviated well section in the North Sea. Several events such as pack-off occurred frequently due to poor hole cleaning and wellbore restriction. The diameter of the well section was $81 \frac{1}{2}$ inch, starting from $5120 \mathrm{~m}$ and ending at $6240 \mathrm{~m}$ measured depth. The previous casing depth was at $5120 \mathrm{~m}$. The casing is a large-diameter steel pipe lowered into the hole to keep the hole section stable. There is no point in making a case in depths above $5120 \mathrm{~m}$ with respect to the hole cleaning and wellbore restriction.

The whole drilling operation was digitized into 163 cases, marked with figures from 1 to 163 . Sometimes due to operational problems real-time data were not available. In Figure 6 the dashed lines depict where there is no real-time data during the drilling operation. The topmost curve shows a drilling process that starts at $5120 \mathrm{~m}$ and follows with circulation process.

\section{RESULTS AND DISCUSSION}

In order to provide a good classification and later employing the right repair actions based on previous experiences, cases were divided into groups with respect to their operational activities; drilling, reaming and backreaming, tripping in (RIH), tripping out $(\mathrm{POOH})$, circulating and connection. Each group includes some classes which are defined later on. 


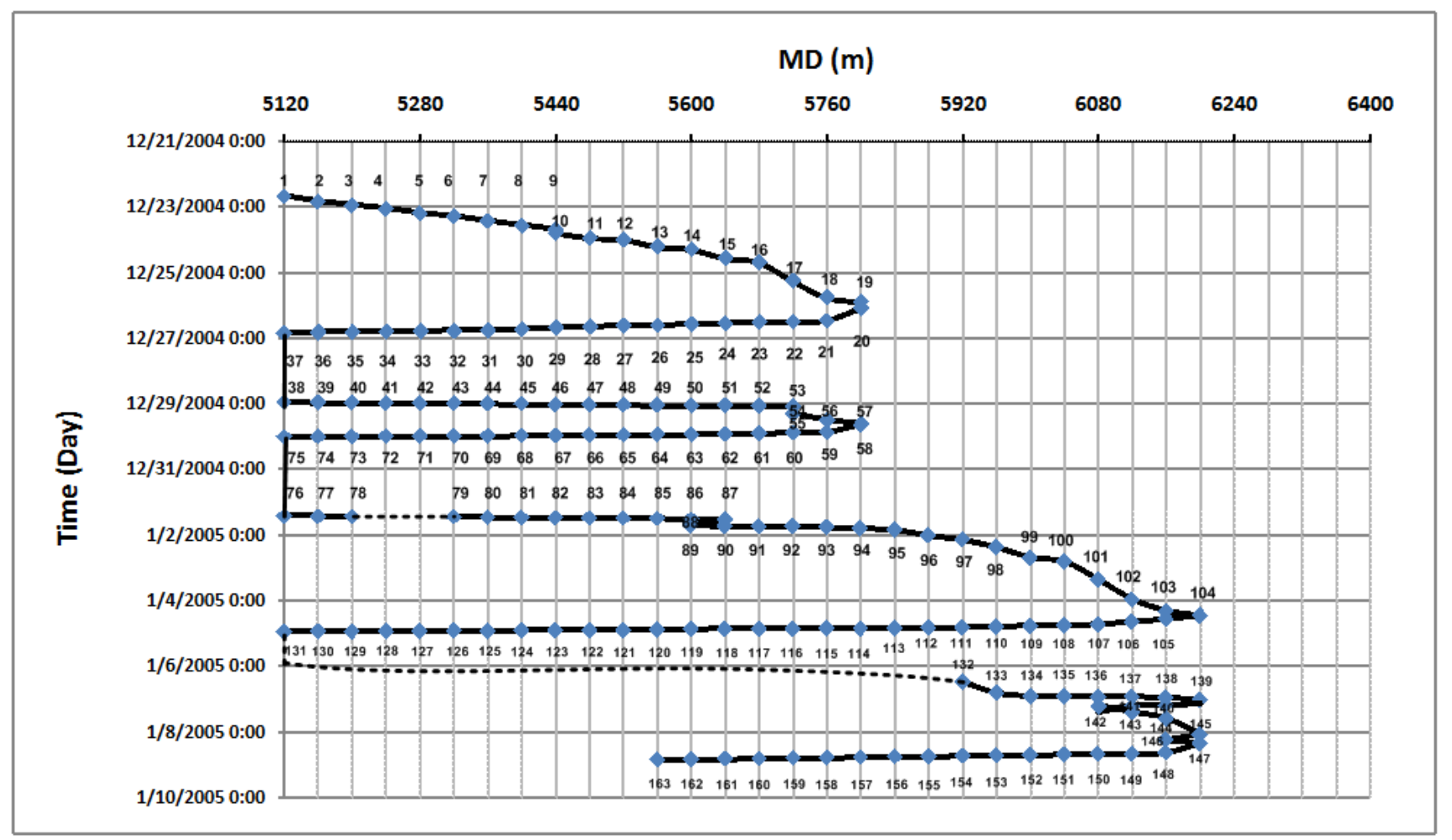

Figure 6. Digitized cases in a bit measured depth vs. drilling time plot.

The number of cases based on their activities is: 29 for drilling activity, 33 for tripping in, 43 for tripping out, 21 for reaming and backreaming, 35 for circulation, and 2 for connection. For each case all the features were provided and 163 cases were introduced to the CREEK system. Based on the activities, cases from 1 to 19 are the cases that occurred while drilling. Each case is compared with cases of the same activity. In the following the two first activities, drilling and tripping in, will be discussed in more detail.

\subsection{Drilling activity}

Figure 7 shows 29 cases within the activity of drilling. They correspond to two sets of cases shown in Figure 6 where depth increases with time. In Figure 7 we also see that there are 5 classes according to the algorithm explained in section 3. Most of the cases were categorized in class 2, stated as hard stringer i.e. a relatively small portion of harder earth formation. As mentioned before cases have different severity and classes. In the rest of the classes there are one or two cases as drilling is the main activity. These classes are soft formation, normal condition, hard formation and reactive formation respectively.

Detailed study reveals that the lithology of the area consists of a relatively uniform claystone package down to the reservoir. The claystone is interbedded with sandstone and limestone stringers. Why are the hard stringers important to reveal? Instantaneous reduction in rate of drilling occurs while drilling through hard stringers. Hard stringers can make directional changes when entering and exiting the hard stringer. Washouts are created in softer formation in front of stringers due to mechanical and hydraulical wear around large outerdiameter (OD) components. Thereafter, produced materials easily accumulate in such hole enlargements. During RIH and $\mathrm{POOH}$ activities different kind of events such as took weight and tight spot will occur.

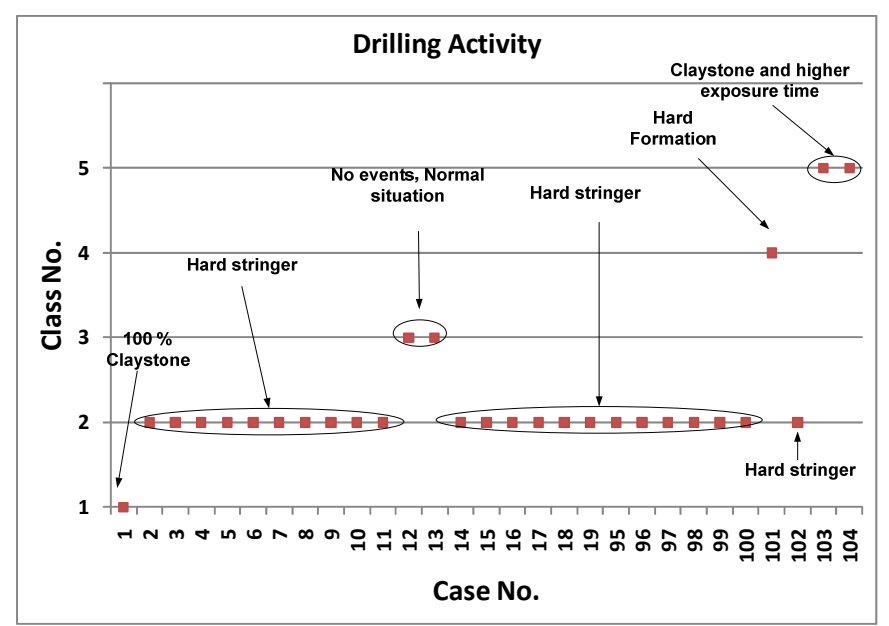

Figure 7. Case classification during drilling activity.

If hole cleaning is found to be in good condition, drilling continues with the established parameters. The classification proceeds deeper into the cases' features and reveals the main differences among unsolved and solved cases. In the studied well section, there were no major problems during the drilling activity and the classes are mostly informative to prevent problems when the other activities happen. 


\subsection{Tripping in (RIH) activity}

The drill string is pulled out of the hole for several reasons. For example, the bit has dulled and must be replaced by a new one to drill efficiently. Once the job is done, the drill string is run again into the hole to continue the drilling activity. But sometimes the RIH activity may take several hours and several repair activities may become necessary. Out of 163 cases 33 cases were categorized as RIH activity. Cases with RIH activity are shown in Figure 8. They are classified into 6 classes according to the similarity assessment and experts' revision. Class 3 consists of the largest number of cases and states normal situation. No abnormal downtime or failures were seen in these cases.

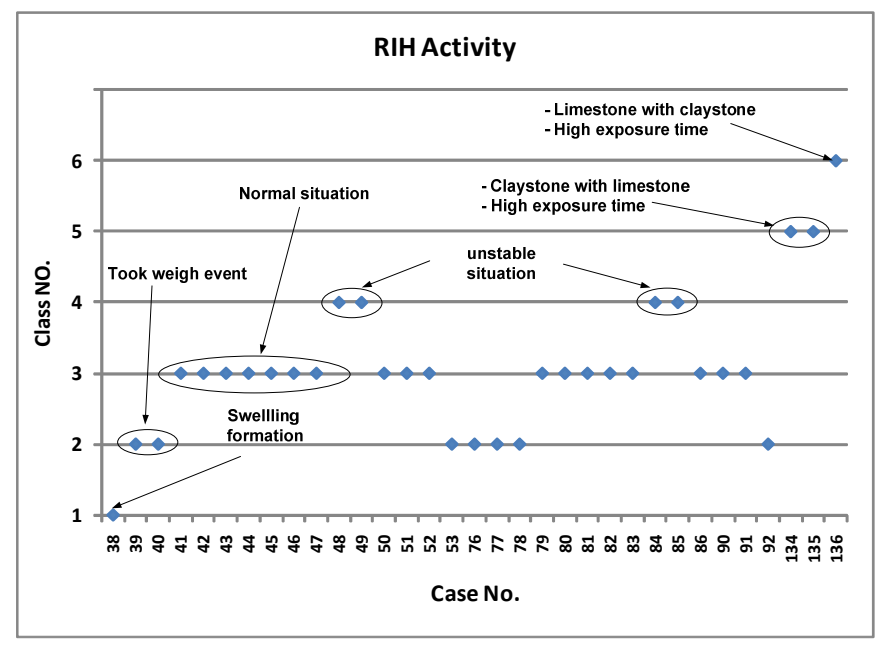

Figure 8. Case classification while RIH activity.

Class 1 has only one case, case 38, titled as swelling formation. Cases in class 2 have experienced took weight while RIH. Cases in class 5 and 6 include claystone with limestone and limestone with claystone respectively. All the cases in class 5 and 6 were exposed to drilling fluid for a long time. It means that they got enough time to react with drilling fluid.

\section{Conclusion}

In real world domains domain, a robust case-based reasoning system will benefit significantly from an automatic case building and case discrimination process. The application of a new methodology to help the drilling personnel choosing the right action has been studied. Unplanned process problems need to be resolved fast. Remedial actions have not been standardized and are often inefficient. When new problems are reported, the solution from a similar situation with the same kind of problems can be reused and adapted to the new problem.

The paper describes a combined manual knowledge acquisition and machine learning approach, which starts with a discretization of cases and accumulate experiences via demonstrations of viable solutions in the process of solving problems. The amount of cases is important in most CBR approaches. Few cases in the case database make the system vulnerable. We managed to make 163 cases and categorized them with respect to the operational activities. In addition, cases were classified into classes according to the similarity assessment and experts' revision. The system has been shown promising results in the oil well drilling.

\section{FUTURE WORK}

This research work describes how to retrieve similar situations for a new case by using the case's features. This work should be applied to different wells as we get access to new information and data. In addition, forming classes is a potential work for building sequences, i.e. the temporal linking of cases of the same class occurring at the same depth intervals. Our aim is to implement the sequence building for the purpose of predicting problems before they occur.

\section{ACKNOWLEDGMENT}

\section{REFERENCES}

1. Aamodt, A. and E. Plaza, Case-Based Reasoning: Fundamental Issues, Methodological Variations, and System Approaches. Artificial Intelligence Communications, Vol. 7, No. 1, pp. 39-59, 1994.

2. Perry, P.B., Curry, D.A., Kerridge, J.D., Lawton, J., Bowden, D., Flett, A.N., A Case Based Knowledge Repository for Drilling Optimization. IADC/SPE Asia Pacific Drilling Technology Conference and Exhibition, 13-15 September, Kuala Lumpur, Malaysia, 2004.

3. Kravis, S. and R. Irrgang, A Case Based System for Oil and Gas Well Design with Risk Assessment. Applied Intelligence, Vol. 23, No. 1, pp. 39-53, 2005.

4. Skalle, P., Sveen, J. and A. Aamodt, Improved Efficiency of Oil Well Drilling through Case-Based Reasoning. Proceedings of PRICAI 2000, Sixth Pacific Rim International Conference on Artificial Intelligence, Melbourne, August- September, 2000.

5. Abdollahi, J., Carlsen, I.M., Randhol, P., Tenold, E., Haga, H.B. and T. Jakobsen, A Case-Based Approach to Understand the Complexity of Causal Connections Related to Well Integrity Problems. IADC/SPE 111129-MS, presented at the IADC/SPE Drilling Conference, Orlando, Florida, USA, 4-6 March, 2008.

6. Shokouhi, S.V., Aamodt, A., Skalle, P. and F. Sørmo, Determining root causes of drilling problems by combining cases and general knowledge. Lecture Notes in Computer Science, Springer-Verlag, ICCBR2009, pp. 509-523, Seattle, July, 2009.

7. Guilherme, I.R., Serapi, A. B. d. S., Rabelo, C. and J.R.P. Mendes, An Ontology Based for Drilling Report Classification. Advances in Artificial Intelligence, Proceeding of 5th Mexican International Conference on Artificial Intelligence, MICAI, pp. 1037-1046, Apizaco, Mexico, November, 2006. 
8. Aamodt, A., Knowledge-Intensive Case-Based Reasoning in CREEK. Advances in case-based reasoning, Lecture Notes in Artificial Intelligence, LNAI 3155, Springer-Verlag, 7th European Conference, ECCBR 2004, pp. 1-15, Madrid, Spain, August/September, 2004.

9. Brüninghaus, S. and K.D. Ashley, Combining ModelBased and Case-Based Reasoning for Predicting the Outcomes of Legal Cases. Lecture Notes in Computer Science, Springer-Verlag. LNAI 2689. pp. 65-79, ICCBR-03, Trondheim, Norway, June, 2003.

10. Grimnes, M. and A. Aamodt, A Two Layer CaseBased Reasoning Architecture for Medical Image Understanding, in Proceedings of the Third European Workshop on Advances in Case-Based Reasoning. 1996, Springer-Verlag.

11. Arcos, J.L., deMántaras, R. L. and X. Serra, Saxex: A case-based reasoning system for generating expressive musical performances. Journal of New Music Research, Vol. 27, No. 3, pp. 194-210, 1998.

12. Skalle, P. and A. Aamodt, Knowledge-based Decision Support in Oil Well Drilling. Proceedings of the ICIIP, International Conference on Intelligent Information Systems, Beijing, 21-23 October, 2004.

13. Popa, A., Popa, C., Malamma, M. and J. Hicks, CaseBased Reasoning Approach for Well Failure Diagnostics and Planning. SPE 114229-MS, presented at the SPE Western Regional and Pacific Section AAPG Joint Meeting, Bakersfield, California, USA, 29 March-2 April 2008.

14. Datta, B.K., Ratnayake, C., Saasen, A., Omland, T.H., Hole Cleaning and Pressure-Loss Prediction From a Bulk Transport Perspective. SPE 96315-MS, presented at Offshore Europe, Aberdeen, United Kingdom, 6-9 September, 2005.

15. Shokouhi, S.V., Aamodt, A., Skalle, P. and F. Sørmo, Comparing two types of knowledge-intensive CBR for optimized oil well drilling. Proceedings of the 4th Indian International Conference on Artificial Intelligence (IICAI-09), Tumkur India, December, 2009.

16. Rasi, M., Hole Cleaning in Large, High-Angle Wellbores. SPE 27464-MS, presented at the SPE/IADC Drilling Conference, Dallas, Texas, 15-18 February 1994. 